\title{
Ruminações do contemporâneo e a suavidade no tempo de digestão
}

FERRAZ, Maria Cristina F.

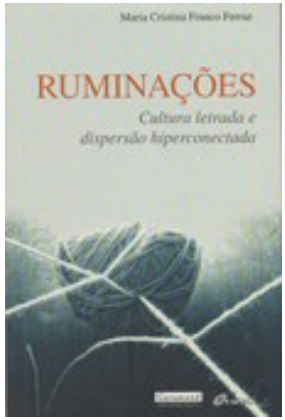

Ruminações.

Rio de Janeiro: Garamond, 176 p., 2015.

Resumo: O livro de Maria Cristina Franco Ferraz propõe modos de escape à dispersão do presente a partir de uma nova instauração da cultura letrada. Diante dessa questão central, o que a obra busca é uma ruminação do contemporâneo e não apenas o seu consumo imediato, ou, uma suavidade digestiva em torno da multiplicidade produtiva. Em vez de um cérebro para dar conta de todos os afetos, vários estômagos para absorver o alimento do presente.

Palavras-chave: ruminações, contemporâneo, suavidade, digestão, cultura letrada.

Abstract: Ruminations of the contemporary and the softness in the time of digestion - Maria Cristina Franco Ferraz's book proposes ways of escaping the dispersion of the present from a new establishment of literate culture. Facing this central question, the work seeks a rumination of the contemporary and not only its immediate consumption or a digestive softness around the multiplicity of production. Instead of a brain to give an account of all the affections, multiple stomachs to absorb the nourishment of present.

Keywords: contemporary; literate culture; consumer culture.

Notadamente o contemporâneo se emaranha em uma diminuição do espaço público e na ampliação do espaço privado do Eu, nas redes e na cena social das ruas, dos parques privados aos condomínios. Se demanda, portanto, uma reflexão sobre 
o contemporâneo, as mediações e seus processos, e essa é uma das chaves em que a teórica e professora titular da Universidade Federal do Rio de Janeiro (UFRJ), Maria Cristina Franco Ferraz encontra para construir uma inversão, ou, como ela mesma afirma, "revirar as vísceras do pensamento" (FERRAZ, 2015, p. 11). Deixar uma racionalização de lado e tentar aproximar pensamento e potência na elaboração do presente, estender a ruminação ao invés de tragar a comida rapidamente. Seu debate se inquieta por algo que Gilles Deleuze nomeou como uma ausência de vácuos de solidão e "de silêncio a partir dos quais elas teriam, enfim, algo a dizer" (DELEUZE, 1992, p. 162). Quem teriam, afinal? As pessoas, os perfis, seus avatares, enfim, os corpos. Uma questão pensada por Deleuze, em que as forças repressivas querem que esses corpos exprimam, tomem o espaço público com suas inquietações narcísicas e reafirmem seu enquadre numa configuração hegemônica dos saberes em circulação, e que Ferraz equaciona ao oferecer uma suavidade, "pois é essa a condição para que se forme algo raro ou rarefeito, que merecesse um pouco ser dito" (FERRAZ, 2015, p. 163).

Mais do que oferecer, Ruminações é, em si, um exercício de suavidade. O ato de ruminar ao invés de rapidamente engolir o que se recebe, de se ter paciência com o alimento nem sempre agradável de levar à boca, traduz um pensamento que não reflete muito sobre o gosto da comida, ação cerebral, mas sobre a digestão e como as vísceras e a barriga lidarão com esse conteúdo e inventarão, elas, as saídas no contemporâneo.

\begin{abstract}
E pensar, portanto, diz respeito ao corpo em sua função mais espiritual: não apenas digerir humanamente, mas mastigar e remastigar, ruminar. Isso requer, obviamente, atenção, concentração e uma necessária abertura a temporalidades mais distendidas. Pensar criticamente equivaleria a ativar uma digestão que demanda vários estômagos, tal como no processo de nutrição dos bois. Nada menos fast-food. Nesse processo, novas potências do corpo são ativadas, à medida que sucessivos estômagos vão sendo produzidos (Idem, p. 17-18).
\end{abstract}

Não por outro caso esse é o caminho escolhido pela teórica em seu livro ao trazer Agamben e Nietzsche em sua afirmação: "Ser contemporâneo requer saudável descompasso com seu próprio tempo, certo anacronismo produtivo" (Ibid., p. 12). Em articulação com o slow down proposto, Ferraz compôs essa obra com nove ruminações originadas de sua bolsa de produtividade e apresentadas em diversos momentos de sua pesquisa. Todas elas têm como eixo o pensamento de uma cultura letrada como um modo de abertura de vácuos no tempo, e espaços que possibilitam uma crítica à nova razão do mundo - pensada por ela como dispersão hiperconectada.

A primeira ruminação tensiona os modos ativos de pensar e ensinar na atualidade, centrados na aceleração dos processos e em uma suspensão das experiências possíveis; "pessoas assistindo a uma conferência ao mesmo tempo que leem outros textos (mesmo no suporte livro) (...) em um regime multitarefado de atenção fragmentada já bastante arraigado nos corpos" (Ibid., p.16). Perceber tais processos seria um modo de avaliação do 
presente e uma proposta ao contemporâneo, em se exercitar mais a escuta e a ruminação do ruído do mundo.

Isso reverbera na segunda ruminação descrita no livro, sobre a cultura somática, em que a farmacologia atua nos corpos para lhes oferecer condições de performatizar no presente, como por exemplo, o cloridrato de metilfendriato, ou, Ritalina, "que é também utilizado por executivos e candidatos que prestam concursos, a fim de maximizar a concentração nos estudos e no trabalho, biorregulando o corpo segundo pesadas demandas produtivistas" (Ibid., p.34). O contraponto a isso, segundo a autora, estaria em certa literatura que expõe essa verdade aos seus ruídos apagados e elabora modos de tensão entre ela e a cultura somática.

\begin{abstract}
A ambiguidade instala-se de uma vez por todas no romance. Enquanto a moldura cultural (a cultura somática) a que ela adere orienta fortemente tanto a produção cultural quanto a recepção da obra, o recurso a outra matriz cultural, em que a experiência não se patologiza mas se desdobra em um plano ontologicamente pregnante, parece também apontar para um crítica implícita a reducionismos de cunho somatizante (Ibid., p. 39).
\end{abstract}

A terceira ruminação persiste na afirmação de uma cultura letrada que inverte a cultura da aceleração somática. Traz na figura de Bartleby a revisão necessária para constatar essa inversão, ou uma suspensão: "Suspensão da frase; suspensão da injunção" (Ibid, p. 51). Uma suspensão em várias dimensões que consolidam uma fissura, um estranhamento.

Em uma quarta ruminação apropria-se mais uma vez do estranhamento em Bartleby para igualá-lo ao extemporâneo na obra de Kafka, em especial uma, intitulada Na colônia penal. A partir da leitura de Deleuze e Guattari na conhecida obra escrita pelos dois filósofos, Kafka: Por uma literatura menor, em que o escritor é descrito como um intimista, alegórico e absurdo. Na quinta ruminação outras metafísicas se mostram possíveis e o canibalismo ameríndio aparece pela literatura do antropólogo Eduardo Viveiros de Castro, em uma ação de degustação que escapa à aceleração do presente. A sexta dedicação ruminante se dá em relação ao corpo. Esse, o qual se colocou um lugar de recalcamento é, em mesma medida, um lugar de expansão frente à cultura ocidental.

Há também na obra um ir e vir dos conceitos propostos, que se assemelham ao ato de digestão dos bovinos, que não se livram do alimento, mas o fazem o retornar sempre de outra maneira. As ruminações sete, oito e nove lidam com uma atemporalidade das relações já desenvolvidas nos capítulos anteriores, como as porosidades dos tempos e dos discursos, dos textos, a figura de Zaratustra em Nietzsche e Machado de Assis, como uma literatura de inversão reflexiva: o espelho machadiano. Em certo sentido, o ato de digestão é um ato reflexivo à mastigação, pensamento e potência na ruminação do contemporâneo.

Agora é voltar ao livro. 
Thiago S Venanzoni é doutorando pela ECA/USP, com bolsa da Fapesp. É pesquisador do Grupo de Estudos da Linguagem: Práticas Midiáticas (MidiAto).

thiago.venanzoni@gmail.com

\section{Referências}

DELEUZE, Gilles. Conversações. São Paulo: Editora 34, 1992.

FERRAZ, Maria Cristina Franco. Ruminações: cultura letrada e dispersão hiperconectada. Rio de Janeiro: Garamond, 2015. 